\title{
El bloqueo hormonal precoz mejora la sobrevida luego de la cirugía locoregional de los pacientes con cáncer de próstata
}

Immediate hormonal therapy compared with observation after radical prostatectomy and pelvic lymphadenectomy in men with nodepositive prostate cancer. Messing E M, Manola J, Sarosdy M. N Engl J Med. 1999; 341: 1781-1788

\section{Objetivo}

Evaluar si el bloqueo hormonal instalado precozmente luego de la cirugía en pacientes con cáncer de próstata con ganglios pélvicos positivos mejora la sobrevida.

\section{Diseño}

Ensayo clínico randomizado con un seguimiento medio de 7.1 años.

\section{Lugar}

Estudio llevado a cabo en seis centros de EE.UU. pertenecientes al Eastern Cooperative Oncology Group.

\section{Pacientes}

Cien hombres con diagnostico clínico de cáncer próstata localizado (hasta T2) sometidos a cirugia (prostatectomía radical más linfadenectomía) y que en la revisión de anatomía patológica se descubren la existencia de ganglios comprometidos por tumor.

\section{Intervención}

Se randomizó a los pacientes a recibir o no terapia antiandrogénica luego de la cirugia (aplicación mensual del análogo LH-RH goserelin, u orquiectomía bilateral).

\section{Medición de los resultados principales}

El resultado principal se definió como muerte asociada a progresión

de la enfermedad. Se analizó además la recaída local y a distancia. Se compararon las curvas de de sobrevida global y el tiempo hasta la progresión.

\section{Resultados principales}

Se registraron mayor número de muertes en el grupo control en comparación con el grupo tratamiento $(18 / 51$ vs $7 / 47)(p=0.02)$. La causa de muerte fue debido a progresión de cáncer de próstata más frecuentemente en el grupo control ( 16 vs 3 pacientes) ( $p=0.01$ ). La sobrevida libre de enfermedad fue más prolongada en el grupo de pacientes con tratamiento hormonal temprano ya que el $77 \%$ estaba vivo y libre de enfermedad, comparado con el $18 \%$ del grupo control en la última actualización del seguimiento $(\mathrm{p}=0.001)$.

Excepto por el tratamiento, ninguna otra variable analizada pudo explicar las diferencias en sobrevida y recaídas (nivel de antígeno prostático específico (PSA) y fosfatasa ácida, grado histológico, extensión local, volumen tumoral, número de ganglios positivos y tipo de terapia antiandrógena).

\section{Conclusiones}

La instauración de tratamiento antiandrógeno tempranamente luego de la prostatectomía radical con linfadenectomía mejora la supervivencia y reduce el riesgo de recaídas en pacientes con ganglios positivos.

Fuente de financiamiento: Becas de Servicios de Salud Pública de EE.UU.

\section{COMENTARIO}

Ya es sabido que el bloqueo hormonal demostró ser eficaz en el tratamiento del cáncer de próstata en otras cirscuntancias. En el ámbito del tratamiento de la enfermedad avanzada luego de los datos publicados en 1967 por el Veterans Administration Cooperative Urological Research Group ${ }^{1}$, parecía ser un dogma que el tratamiento hormonal pre$\mathrm{COz}$ (orquiectomia o estrógenos) si bien logra remisiones mayores, no mejora la supervivencia de los pacientes. Sólo un trabajo de la clínica Mayo, controvertido por su diseño retrospectivo y con inconvenientes en la homogeneización de los grupos a comparar, encontró beneficio en tratar pacientes con cáncer de prostata de células diploides, siendo notable la diferencia sólo luego de diez años de seguimiento y con un beneficio atribuible mucho menor. En 1997 en un trabajo aleatorizado ${ }^{2}$ se encontró ligero beneficio con el tratamiento hormonal precoz. Este beneficio fue mas importante al evitar complicaciones severas asociadas a la evolución del cáncer de próstata (fracturas patológicas, insuficiencia renal obstructiva, compresión medular).

En el ámbito neoadyuvante y adyuvante en conjunto con radioterapia varios estudios demostraron mejoría en el tiempo a la progresión pero no de la supervivencia global. Tal vez la reducción del tamaño prostático por las hormonas mejore el resultado local de la radioterapia pero es incierto que pueda controlar la enfermedad micrometástasica. Algunas observaciones hacen presuponer que el tratamiento hormonal sería más efectivo cuando la carga tumoral es mínima, por eso el uso luego de cirugía satisfactoria de la enfermedad localmente avanzada sería un modelo ideal.

Es de hacer notar igualmente que el hecho de tener ganglios positivos no siempre significa tener enfermedad diseminada micromestatásica, ya que por ejemplo en este trabajo casi el $20 \%$ de los pacientes tratados sólo con cirugía gozaron de sobrevidas prolongadas libres de enfermedad (¿curación?).

Hay varios inconvenientes al evaluar la extensión de enfermedad en pacientes con cáncer de próstata. La estadificación inicial suele ser ineficaz con los métodos por imágenes y de laboratorio actuales (la estadificación quirúrgica es menos frecuente debido al creciente uso de novedosas técnicas de radioterapia), es imposible reconocer enfermedad mínima luego de la cirugía, tal vez el uso de PSA ultrasensible o basarse en factores de riesgo nos puedan predecir cuales pacientes puedan beneficiarse más con el tratamiento precoz.

A medida que progresamos nuevas preguntas surgen: ¿es lo mismo utilizar tratamiento hormonal sólo o la combinación hormonas más cirugía es más conveniente en la enfermedad locoregional? ¿Cuál sería el tiempo ideal de tratamiento hormonal adyuvante?; ¿existe alguna ventaja entre las diferentes modalidades de tratamiento hormonal? (principalmente análogos LH-RH vs orquiectomia); ¿el costo justifica la utilización?

Hoy en día, aún faltan estudios para avalar el uso en forma sistemática del tratamiento hormonal en el contexto neo o adyuvante en el cáncer de prostata local o locoregional. 